\title{
La erudición en las Empresas políticas de Saavedra Fajardo
}

\author{
Sagrario López Poza
}

De los muchos juicios que sobre Saavedra Fajardo se han expresado a lo largo de más de trescientos cincuenta años, suele destacar la unanimidad en considerar su obra como de las más eruditas que ha producido la Literatura española. Algunos críticos han estimado ese bagaje como una pesada carga enfadosa y pedante que impide disfrutar a plena satisfacción del contenido del discurso, mientras que otros se admiran de la memoria y capacidad del autor que hace posible traer a colación una cita de clásicos o bíblica, una anécdota histórica, un dicho de un famoso, un ejemplo de la historia contemporánea para ilustrar y refrendar la argumentación que sigue. Quienes han sido benévolos en el juicio, sin embargo, suelen enseguida pasar a considerar la cuestión de la originalidad de Saavedra, y con el mismo afán que dedican a averiguar sus fuentes (expresas o no), muestran la desilusión que les causa hallar en otros autores ideas o motivos que Saavedra ha utilizado en sus Empresas.

Va siendo hora de considerar la erudición que puebla las páginas de las Empresas politicas teniendo en cuenta el contexto cultural en que se produjeron $\mathrm{y}$, desde luego, desdeñar cualquier juicio negativo en torno a la originalidad de su autor, que era un asunto que en absoluto preocupaba a una mente cultivada del siglo XVII en el sentido en que sólo a partir del Romanticismo se ha venido aplicando.

En la época en que Saavedra escribe, la erudición era estimadísima, de lo que dan fe las cartas que le dirige el famoso intelectual europeo Henri Van de Putte (Erycius Puteanus) y que él inserta al comienzo de la segunda edición de las Empresas. Aunque se trata de cartas en latín en estilo muy retórico y de carácter panegírico, de las que tenemos que limar las exageradas alabanzas, es notable lo mucho que destaca la admiración por la erudición del español, que revela sincera estima, y que haría sentirse muy orgulloso a nuestro Saavedra. Encomia el ingenio de que la Naturaleza le dotó y el esfuerzo dedicado a adquirir conocimientos, así como la habilidad en el empleo del método de saberlos acopiar para emplearlos cuando fuera oportuno con el fin de provocar deleite y aprovechamiento en sus lectores. Ensalza también que la erudición sea variada (profana y sagrada):

Desde luego, hay aquí una obra digna del supremo ingenio que la Naturaleza te otorgó; de la suma erudición que te confirió la diligencia y la familiaridad con las cosas y los estudios. Tuya es esta gloria, oh Fénix de los varones, que en un solo volumen, y en un ciento de imágenes has podido abarcar lo que no muestran mil libros de otros. Aquí se encuentra lo que está en todas partes, lo que contienen los tiempos antiguos y los nuestros, lo sagrado y lo 
profano. Los ejemplos son como antorchas, las sentencias como gemas, la obra entera no es sino oro, que será estimado en todo censo de doctrina, y por todos, incluida la posteridad. Adelante, pues, que sea materia pública, que enseñe a todos los príncipes cómo ser verdaderamente príncipes: gobiérnense a sí mismos y a los demás, sean felices y hagan felices a los otros no menos con su ejemplo que con su imperio. Este es ahora un deseo mío, pero un logro tuyo, que los principes y los pueblos pondrán en la cuenta de tu ingenio y de tu erudición ${ }^{1}$.

Importa, por tanto, considerar lo que se entendia por «erudición» en el entorno cultural en que se mueve Saavedra, y para ello conviene tener en cuenta lo que escribían tratadistas y educadores contemporáneos, como el padre jesuita Nicolas Caussin, en su obra de enorme fama e influencia De eloquentiae sacrae et humanae parallela libri $X V I$, editada en numerosas ocasiones desde 1619 y que dedicó a Luis XIII en agradecimiento por la reapertura del colegio de los jesuitas de Clermont ${ }^{2}$. La obra ofrece un universo de cultura práctica destinada a cortesanos cristianos que aspiran a ser eruditos. Distingue el Padre Caussin la elocuencia heroica (la de la iglesia) frente a la humana (la de la sociedad civil) y reparte la materia destinando XIII libros a la humana, frente a III libros a la heroica. En esa obra se encuentran todo tipo de indicaciones para el empleo de géneros oratorios profanos como el memorial, el elogio, la sátira, la vituperación, y géneros oratorios sagrados, como la homilía, el sermón, el panegírico de santos, la controversia... todo ilustrado con una enorme cantidad de ejemplos latinos y griegos y citas clásicas que como en una poliantea se ofrecen al lector en latín elegante, en un estilo ameno y animado, lleno de prosopopeyas, diálogos, descripciones, $y$, de vez en cuando, se permite muestras de entusiasmo o de indignación ${ }^{3}$.

Caussin se hace eco de la viva polémica que hay en el momento en torno a si es preciso que el discurso sea erudito y plantea las dos posturas enfrentadas: unos parece que tienen declarada la guerra a la erudición, a la que consideran oropel y la califican de huera, y centran su atención en la estructura y en la disposición de las palabras, y así logran soltura y concisión, pero no extraen a los temas vigor y riqueza. Otros, por

1 Traducción de Fernando González Muñoz, inserta en mi edición de las Empresas políticas de Saavedra Fajardo para editorial Cátedra, Madrid, 1999.

2 Flexiae, sumpt. S. Chappelet, 1619. Tuvo la segunda edición en 1623 , y de 1623 a 1686 hubo al menos cuatro reediciones en París, tres en Colonia y cuatro en Lyon.

3 Conviene aquí aclarar que cuando hablamos de orador no nos referimos «strictu sensu» a los que elaboran sermones o discursos destinados a ser pronunciados en el púlpito, las asambleas, el foro, los tribunales o el senado, como podria entenderse. En la segunda mitad del siglo XVI, se había puesto muy de moda una variedad de prosa discursiva, con finalidad didáctica, como sustitutoria o coaligada de la comunicación hablada. El lector se concibe como oyente, y se apela a él como si pudiera contestar inmediatamente a manera de coloquio. Se establece asi una cercanía entre emisor y receptor del mensaje que refuerza los vínculos precisos para que la persuasión sea eficaz. Ver Asunción Rallo Gruss, «Tópicos y recurrencias en los resortes del didactismo: confluencia de diferentes géneros», Criticón, 58, 1993, 135-154. 
estimar que el orador o escritor debe ser docto, atiborran los discursos de historias y de testimonios sin criterio alguno, y torpes en su expresión, se preocupan sólo de aclarar el variopinto ajuar de su erudición.

El método para ser diestro en oratoria requiere, según Caussin, equilibrio y considerar con mucho cuidado qué permite o exige el tema, qué la situación y qué los oídos del oyente (y en el caso de los discursos escritos, el lector). Los oradores prudentes, aunque de vez en cuando apliquen la erudición, lo hacen con tal destreza, que lo que dicen parece fluir espontáneamente y no que haya sido rebuscado; luego, lo suavizan y aderezan con tantos condimentos que se torna familiar incluso a oídos del pueblo. Lo más importante es acertar en la proporción adecuada de erudición empleada.

El maestro en este tipo de prácticas fue en la segunda mitad del siglo XVI Justo Lipsio, que sorprendía y admiraba a cuantos leían sus obras y tuvo muchos imitadores que no lograban estar a su altura. Baltasar de Céspedes, en su Discurso de las Letras Humanas, dice de Lipsio, considerado modelo de humanista e intelectual:

Este hombre tiene excelencia de juntar con agudeza y juicio los lugares diferentes de los Autores a un propósito, como se ve en aquella admirable obra de la Politica, donde con un perpetuo hilo del sentido va cosiendo diferentes lugares griegos y latinos de tal manera que parece que los mismos Autores los hicieron más para el propósito de Lypsio que para el suyo propio. Este es un negocio de muy fundado estudio, atenta lección, y muy considerada noticia de lo que se lee, y de pronta y feliz memoria y presente representación de todas las cosas.

Quien se preparaba para orador o escritor de una prosa elegante había de adquirir un sólido bagaje en todas las artes liberales y disponer de un método que le permitiera explotar eficazmente el fruto de sus lecturas. Ese método, seguido por los humanistas y aprendido en la infancia, consistía en anotar en el codex excerptorius o cartapacio personal, por lugares comunes, todo cuanto en la lectura había llamado la atención, bien por la forma o por el contenido, esperando poder volver a usarlo en alguna ocasión como motivo de invención o como autoridad para reforzar la argumentación de un discurso. Las instrucciones sobre cómo organizar en lugares comunes todo ese material

4 Discurso de las letras humanas, llamado "El humanista» que según D. Nicolás Antonio escribia en el año de 1600 D. Baltasar de Céspedes, Yerno del Brocense, y su immediato succesor en la Cátedra de Prima de Retórica de la Universidad de Salamanca, y que sale a luz la primera vez, Madrid, Antonio Fernández, 1784, 63. Existe edición moderna de Gregorio de Andrés, El Escorial, 1965. 
pueden hallarse en escritos de Humanistas eminentes como Erasmo ${ }^{5}$, Vives ${ }^{6}$, Salinas $^{7}$ y Palmireno ${ }^{8}$, Baltasar de Céspedes ${ }^{9}$ y Justo Lipsio ${ }^{10}$. Los argumentos eruditos extraídos de todo tipo de saber (historias, axiomas, leyes, comparaciones...) se hallaban así disponibles para ser distribuidos por el discurso procurando soltura, sin amontonarlos, cuando hicieran falta. Sin embargo, ese método genuino fue siendo desvirtuado con la publicación de muchas enciclopedias, florilegios y polianteas que sustituyeron cada vez más el trabajo personal, lo que dio pie a muchas críticas y censuras, la más fina de las cuales puede verse en el prólogo del Quijote. Y es que, a pesar de todas las normas escritas, era una labor de tal dificultad, que el Padre Caussin se ve obligado a incluir entre las fuentes de la invención que nutren la erudición una final que denomina «la razón y el talento aplicados a los lugares comunes», porque sin el ingenio natural «por mucha que sea la erudición, permanecerá la espada escondida en la vaina y su filo quedará sin efecto ${ }^{11} m$.

Con el tiempo se había llegado a ciertas convenciones sobre lo que se consideraban campos del saber susceptibles de ser empleados como adornos eruditos en una obra. Gracián ${ }^{12}$ define la erudición así:

Consiste en una universal noticia de dichos y de hechos, para ilustrar con ellos la materia de que se discurre, la doctrina que se declara. Tiene la memoria una como despensa, llena de este erudito pasto, para sustentar el ánimo, y de que enriquecer y fecundar los convites que suele hacer a los entendimientos. Es un magacén rebutido, un vestuario curioso, un guardajoyas de la sabiduria. Sin

5 Desiderio Erasmo, De copia verborvm, et rervm libri duo. Eiusdem libelivs de ratione studii \& pueris instituendis. Eivsdem de componendis epistolis libellus vtilissimus, cum nonnullis aliis, ad omnium studiosorum vilititate. Compluti, MDXXV.

6 Luis Vives, De tradendis disciplinis, seu de institutione Christiana, en Opera Omnia, Valentiae Edetanorum, in off. Benedicti Monfort, MDCCLXXXV, t. VI. También puede leerse esta obra en la edición en español en Obras completas, II, Madrid, Aguilar, 1948, 337-687.

7 Rhetórica de la lengua castellana en la qual se pone muy en breve lo necessario para saber bien hablar o escrevir, y conoscer quien habla y escriue bien... escrita por un frayle de la Orden de Sant Hieronymo, Alcalá de Henares, Juan de Brocar, 1541.

8 Lorenzo Palmireno, El estudioso de aldea... con las quatro cosas que es obligado a aparender un buen discípulo: que son Devoción, Buena criança, Limpia doctrina, y lo que llaman Agibilia... Valencia, 1568.

9 Baltasar de Céspedes, Discurso de las letras humanas llamado el Humanista, escrito en 1600, pero que se editó por vez primera por Santos Díez González, en Madrid, Antonio Femández, 1784.

10 Iusti Lipsi Epistolica Institutio, excerpta e dictantis eius ore, anno MDLXXXVII mense Iunio adiunctum est Demetrii Phalerei eiusdem argumenti scriptum, cap. XII: «De excerptis; quo ordine ea instituenda, \& a quibus singula carpenda». Puede verse en Opera omnia, Antuerpiae, ex Off. Plantiniana Balthasaris Moreti, 1637 (4 vols.), vol. II, pág. 539 y sigs.

11 Op. cit. IV, VII, 137-138.

12 Baltasar Gracián, Agudeza y arte de ingenio, tratado segundo, discurso LVIII "De la docta erudición y de las fuentes de que se saca», en Obras completas, II, ed. de E. Blanco, Madrid, Turner, [1993], 726-730. 
la erudición no tienen gusto ni sustancia los discursos, ni las conversaciones, ni los libros. Con ella ilustra y adoma el varón sabio lo que enseña, porque sirve así para el gusto como para el provecho (...) pero no ha de ser uniforme, ni homogénea, ni toda sacra, ni toda profana, ya la antigua, ya la modema, una vez un dicho, otra un hecho de la historia, de la poesía, que la hermosa variedad es punto de providencia. Especialmente se ha de atender a la ocasión y a sus circunstancias, de la materia, del lugar, de los oyentes, que la mayor prenda del que habla o escribe, del orador o historiador, es decir con seso.

Indica como fuentes de donde extraer argumentos eruditos:

Historia, así sagrada, como humana,

Sentencias y dichos de sabios, sacados de la Filosofia moral y de la poesía.

Apotegmas, agudezas, chistes, donosidades

Dichos heroicos de príncipes, capitanes, insignes varones

Emblemas, jeroglíficos, apólogos y empresas

Símiles, alegorías, parábolas

Adagios y refranes

Paradojas, problemas, enigmas, cuentos

Y con muy poca diferencia da su clasificación el Padre Caussin:

\author{
Historia \\ Apólogos y parábolas \\ Adagios \\ Jeroglíficos \\ Emblemas \\ Testimonios de los antiguos \\ Sentencias \\ Leyes \\ Las Sagradas Escrituras
}

Saavedra conoce bien estas demandas de la sociedad en que se mueve, y demuestra un dominio perfecto del método al que acabamos de aludir. Se propone adomar las empresas con todo tipo de saberes estimados y cada una de las fuentes de las que nos hablan Gracián o Caussin están representadas en las empresas con distinta proporción. Lejos de las desmañadas maneras de algunos contemporáneos suyos, Saavedra especifica sus fuentes, las localiza con bastante precisión, ostenta sus cualidades de hombre de formación universitaria y profesión vinculada a las letras y destinada al servicio público. Su forma de proceder es emplear sentencias al principio de la 
declaración e ilustrarlas con uno o varios ejemplos o citas después que confirmen lo dicho. Puede verse, como ejemplo, la empresa 33 en que, tras la acumulación de sentencias, se incluyen exempla históricos (anécdotas antiguas y modernas).

Si nos centramos sólo en las citas textuales, que pueden ofrecer datos cuantitativos incontrastables, y atendiendo a la segunda edición de las Empresas politicas (muy aumentada con respecto a la (princeps») tenemos lo siguiente:

Total de citas textuales: 1.855

De distintas obras de Tácito

$$
695(37,46 \%)
$$

de la Biblia

de Juan de Mariana

de Aristóteles

de Alfonso X (Las Partidas)

$158(8,5 \%)$

$86(4,6 \%)$

de Séneca

de Leyes distintas de Las Partidas

De otros autores

El análisis cuantitativo, aunque no debe ser el único, es bastante elocuente. Las obras de Cornelio Tácito (Annales (ab excessu divi Augusti), Historiae, Agricola y Germania) han ejercito tal influencia en la redacción de las Empresas (en especial las dos primeras), que sin duda evidencian una forma de pensar, una ideología bien clara en Saavedra, como ya han advertido algunos críticos ${ }^{13}$. Sólo las citas bíblicas van a la zaga, y juntas unas con otras representan casi las dos terceras partes de las fuentes empleadas. Con todo, conviene aclarar ciertas cuestiones curiosas.

Como es sabido, los cambios que se produjeron entre la redacción de la primera y la segunda edición (Munich, 1640 y Milán, 1642) son notables en muchos aspectos, y es éste de la presencia de citas de Tácito y las bíblicas el más relevante. De la primera edición se eliminan 89 citas textuales de Tácito. Destacan, por el número elevado de las excluidas, las antiguas empresas 19,47 y 42 (que pasan a ser las números 21, 61 y 44 en la edición de Milán) y que se ven privadas respectivamente de 10,21 y 9 citas de Tácito. Hay que decir que eso no significa que se excluya el pensamiento del historiador latino, pues en ocasiones se emplean sus sentencias camufladas en el texto español, sin la identificación expresa de la fuente. El caso chocante de la moderna empresa 61 es muy elocuente al respecto. En la versión nueva, se eliminan 30 citas que

13 André Joucla-Ruau murió antes de terminar un amplio estudio sobre el pensamiento de Saavedra Fajardo, en lo que estaba destinado a ser su tesis doctoral. Parte de ese trabajo redactado en 1962 fue publicado póstumo bajo el título: Le Tacitisme de Saavedra Fajardo (París, Éditions Hispaniques, 1977). En las págs. 13-15 ofrece el recuento total de citas textuales (1.853), especificando las de Tácito $y$ las bíblicas. En el recuento que ahora ofrezco varían ligeramente las cantidades, porque he hallado el autor de algún raro caso en que Saavedra no lo aportaba y porque he procedido a la identificación de las citas, y algunas atribuidas a otros autores resultaron ser de Tácito. 
apoyaban todo el discurso de la declaración de la empresa; de ellas, 21 eran de Tácito, pero ello no impide que el texto siga siendo una taracea de motivos tomados del historiador romano. Por otro lado, en la segunda edición se añaden 41 citas de Tácito en lugares, en donde no se había empleado como fuente en la primera edición.

Respecto a las citas bíblicas, el contraste entre la primera y la segunda edición es más notable. Las 72 citas procedentes de distintos libros de la Biblia que aparecían en la edición de Munich se convierten en 547 en la edición de Milán (es decir, que por cada cita bíblica inicial hay luego más de siete y media). Las empresas de la segunda edición en que la interpolación de citas bíblicas es más ostentosa son la 1, 8, 11, 18, 31, 40,48, $49,50,55,57,62,75,86$ y 101 . Dentro de éstas, a su vez, destacan la 48 (que pasa de 1 cita bíblica a 20), la 50 (que pasa de 0 a 25 ) y la 55 (de 0 a 18). En realidad, muchos de los cambios experimentados en el texto, en su mayor parte bloques añadidos, no son más que fragmentos redactados de manera forzada para hacer que encaje de forma conveniente una cita bíblica que no existía en la primera edición. El fenómeno se observa muy bien, por ejemplo, en la empresa 78, con las citas de los Proverbios y los Salmos. También se observa el fenómeno en las dos últimas empresas, cuya inicial abundancia de citas de Tácito hubo de ser maquillada luego con la inserción de varias procedentes de la Biblia.

Considerando despacio estos cambios, no podemos sino preguntarnos cuál es el auténtico Saavedra, si el que se refleja en la primera edición o el de la segunda. Es evidente que en la primera versión fue más espontáneo, mientras que en la segunda parece actuar aleccionado, advertido de que puede tener problemas si no dosifica convenientemente las fuentes profanas con las sagradas. Su larga ausencia de España tal vez le hacía desconocedor del ambiente rígido que se había ido creando en la península en torno a las fuentes de autoridad profanas, incluidas las mitológicas. Ello explicaría tantos cambios observados en la segunda versión, no sólo en el texto, sino en las "picturae» (fueron eliminadas sistemáticamente de la segunda versión las que tenían referencias mitológicas). La justificación de la inserción de las citas bíblicas en la segunda edición la da él mismo en el prólogo:

con particular estudio y desvelo, he procurado tejer esta tela con los estambres políticos de Cornelio Tácito, por ser gran maestro de príncipes y quien con más buen juicio penetra sus naturales y descubre las costumbres de los palacios y Cortes, y los errores o aciertos del gobierno. Por sus documentos y sentencias llevo de la mano al príncipe que forman estas Empresas, para que, sin ofensa del pie, coja sus flores, trasplantadas aquí y preservadas del veneno y espinas que tienen algunas en su terreno nativo y les añadió la malicia de estos tiempos. Pero las máximas principales de Estado confirmo en esta segunda impresión con testimonios de las Sagradas Letras, porque la política que ha pasado por su crisol es plata siete veces purgada y refinada al fuego de la verdad. ¿Para qué 
tener por maestro a un étnico o a un impío, si se puede al Espíritu Sancto?

Saavedra actuó en su primera intención siguiendo las tendencias al uso. La Historia era el mayor almacén de elocuencia y la principal fuente de erudición, como defendía Caussin, que se pregunta:

\begin{abstract}
¿Qué hay más divino que conocerlo todo, que recorrer como un astro muy raudo regiones muy separadas entre sí, que hacer recuento completo de aquello que de todas las épocas se guarda recuerdo, hazañas, acontecimientos, ejemplos, que contemplar con una única mirada del intelecto el estado, nacimiento, desarrollo, vicisitudes, declive y fin de los imperios? ¿Qué hay más noble que observar reunidos, por así decir, en un solo cuadro el arte de gobernar y el arte de la guerra, representaciones de muy preclaras virtudes, que comparar el pasado con el presente, aprender con el daño ajeno y extraer luego saludables preceptos para perfeccionar la vida, cualquiera que ésta sea? ${ }^{14}$
\end{abstract}

El mismo Saavedra, en el prólogo de su Corona gótica, manifiesta que no hay ningún maestro mejor de los príncipes que la Historia. $Y$ dentro de los historiadores romanos, Tácito se había ganado el prestigio máximo, gracias, sobre todo, a la difusión que adquirió su obra desde la edición de 1574 realizada por Justo Lipsio. Entre otras ediciones, la autoridad que adquirió la del erudito belga se debía a su excelencia filológica, que derivaba del gran conocimiento que tenía de la Literatura, la Historia y las instituciones romanas. Se ha trabajado mucho sobre la recepción de Tácito en la Europa del siglo XVI y XVII, que se perfila en varias vías de influencia en los españoles, entre las que destacan la vía italiana, la más temprana y duradera (con Alciato, Guicciardini, Ammirato, Botero, Boccalini y Malvezzi), la francesa (Mureto, Bodino, Montaigne) y la flamenca o lipsiana ${ }^{15}$. Saavedra, como varios predecesores notables, emplea la sabiduría de la antigua Roma «ad usum vitae». El establecimiento del texto de Tácito no fue para Lipsio un fin en sí mismo, sino un medio de aprovechar

14 Nicolas Caussin, Eloquentiae sacrae et humanae parallela, 1619, libro IV, cap. III, pág. 129. (Trad. nuestra).

15 Ver al respecto el libro de Beatriz Antón Martínez, El Tacitismo en el siglo XVII en España. El proceso de "receptio», Valladolid, Secretariado de Publicaciones, Universidad de Valladolid, 1991. También siguen siendo de interés: J. A. Maravall, «La corriente doctrinal del Tacitismo político en España), Cuadernos Hispanoamericanos, octubre-diciembre 1969, núm. 238-240 (recogido en Estudios de Historia del pensamiento español. Serie Tercera. El Siglo del Barroco, Madrid, Ediciones Cultura Hispánica, 1984, 75-98); E. Tierno Galván, «El Tacitismo en las doctrinas políticas del Siglo de Oro español», Anales de la Universidad de Murcia, curso 1947/48, 895-988 (recogido en Escritos (1950-1960), Madrid, Tecnos, 1971, 13-93; F. Sanmartí Boncompte, Tátito en España, Barcelona, C.S.I.C., 1951; F. Murillo Ferrol, Saavedra Fajardo y la política del Barroco, Madrid, I.E.P., 1957. 
la Historia para enseñar prudencia en asuntos políticos contemporáneos, lo que constituyó la base para hacer una lectura política de Tácito ${ }^{16}$. Lipsio, el ídolo de los españoles de la segunda mitad del XVI y que continuó ejerciendo enorme influencia en el siglo XVII, estaba convencido de la superioridad de Tácito sobre otros historiadores romanos; valoraba sobre todo su «iudicium» y lo consideraba una fuente de sabiduría para entender los sucesos contemporáneos ${ }^{17}$. A Salustio lo consideraba poco independiente de los sucesos que registraba; a Tito Livio, demasiado circunscrito a su material, lo que le hizo registrar asuntos de importancia local, más entretenidos que instructivos. Tácito, en cambio, era un intérprete agudo de las causas de los sucesos, que resultaban ser de interés universal, de modo que pueden obtenerse de él lecciones para generaciones futuras, y además, su juicio histórico fue justo. Y es esa noción de «utilitas» de la Historia narrada por Tácito, la que permite obtener lecciones de buen gobierno y prudencia, la que interesa también a Saavedra.

Lipsio, como erudito, profesor y preceptor de dirigentes de la Iglesia y el Estado, estaba convencido de la utilidad de Tácito para la enseñanza política y se alejó poco a poco de los comentarios filológicos del texto del historiador para acercarse cada vez más a una interpretación política, lo que culminó en una obra concisa y compleja de enorme influencia en su época donde volcó la «prudencia civilis ac militaris» de Tácito y que está en sordina en la redacción de las empresas de Saavedra: Politicorum sive civilis doctrina libri sex, qui ad principatum maxime spectant... publicada por primera vez en Leiden, en 1589. Este manual para los soberanos y sus consejeros no era sino un mosaico de sentencias de Tácito y otros autores clásicos ligadas con un comentario y dispuestas de forma que parece una teoría coherente y aplicadas a la nueva política, lo que permitía a los príncipes católicos y protestantes del momento justificar sus propias acciones. Esta obra está compuesta por cuatro elementos que también están en la de Saavedra: citas, comentario, sumario y referencias a las fuentes, lo que representa un esfuerzo sistemático de reunir el conocimiento de los autores clásicos para un negocio práctico de gobierno en un estado moderno.

16 Lipsio había comenzado a estudiar a Tácito cuando llegó a Roma, en 1569, estimulado por M. A. Mureto, quien había intentado explicar la obra de Tácito en la Universidad de Roma, cuyas autoridades católicas le hicieron desistir de la idea argumentando que Tácito era hostil a los cristianos y a los judíos. Mureto mostró en Roma a Lipsio sus notas sobre Tácito, y se sintió plagiado cuando luego el joven discípulo llevó adelante con tanto éxito su plan fallido. Lipsio, por su parte, dedicó por lo menos treinta y siete años a Tácito (desde la primera edición, de 1574), y a su muerte, en 1606, estaba preparando una edición con sustanciosos comentarios (que dio a la imprenta su discípulo Woverius en 1607).

17 En las notas al cap. IX del I libro De memoria et rerum Lipsio manifiesta la superioridad de Tácito sobre Tito Livio y Salustio, merced a su prudentia y iudicium. La primera se muestra según él en la sabiduría política del historiador, el segundo, en su elección del material, su fidelidad a la verdad histórica y su perspicacia moral y psicológica. A ello se une el estilo lacónico y sentencioso que hace de tu texto un florilegio de preceptos para los políticos contemporáneos, tanto los príncipes como sus consejeros. 
Además de Tácito, Saavedra emplea citas de otros autores clásicos que escribieron sobre Historia, como Quintus Curtius Rufus (Historiae Alexandri Magni), M. Annaeus Lucanus (De bello civili), Polybius (Historiae), T. Livius Patavinus (Ab urbe condita librorum periochae), Diodorus Siculus (Bibliotheca historica), Eusebio Caeserensis (Historia ecclesiastica y De vita Constantini) y Velleius Paterculus (Historia romana). A algunos de ellos los cita con frecuencia, como a Tito Livio, del que toma 18 citas, o a Salustio (5 citas).

No bastaba acudir a la Historia antigua para obtener ejemplos didácticos que ilustraran y advirtieran al joven príncipe. Como Caussin recomendaba, era preciso tener abundantes ejemplos disponibles también de la historia cercana y aun cotidiana. De los historiadores españoles, Saavedra emplea con profusión al Padre Juan de Mariana, cuya Historia general de España había sido compuesta primero en latín (Historiae de rebus Hispaniae libri XXV, Toledo, 1592) y luego traducida al castellano por él mismo. También emplea los Anales de Aragón de Zurita y las obras históricas de Antonio de Nebrija.

No pensemos, sin embargo que la Historia se utiliza siempre para ilustrar con «exempla» virtuosos. A veces se acude a ella para mostrar muchos comportamientos sagaces o astutos que proporcionaron triunfos a los personajes notables que se citan como paradigma de actuación política. En la empresa 42, por ejemplo, vemos cómo «Para incitar Seyano a Druso a la muerte de su hermano Nerón, le arrojó delante la esperanza del Imperio» y se ilustra con una cita de los Annales de Tácito.

Si sumamos a las citas de historiadores clásicos las de los modernos, tenemos que la mitad de las citas de las Empresas proceden de la Historia. Y ello si mantenemos aparte las citas bíblicas, cuyo interés en la mayor parte de las ocasiones se manifiesta también con ánimo de ilustrar aspectos de la historia del pueblo hebreo, en donde se pueden hallar ejemplos edificantes para el gobernante moderno. Es por esa razón por la que los libros bíblicos que predominan son los históricos. De modo que, si tenemos esto en cuenta, casi un $80 \%$ del total de citas se habrían basado en textos de Historia profana o pagana, antigua o moderna.

Como hemos visto, entre las fuentes que indica el Padre Caussin a donde hay que acudir en busca de erudición están las Leyes, pues proporcionan gravedad, prudencia y riqueza al discurso, y en efecto, en las Empresas es importante la proporción de citas procedentes de obras de carácter jurídico. Destaca sobremanera la presencia de citas de Las Siete Partidas de Alfonso X, inspiradas en las más puras fuentes del Derecho romano, pero que tienen en cuentan la tradición viva y operante de Castilla. A Saavedra parece haberle interesado en especial la partida segunda, que adquiere en varias partes la forma de un tratado de regimiento de príncipes. Suele emplear largos fragmentos de texto de las Partidas y por ello son las únicas citas que inserta en medio de su «declaración» y no en el margen, como el resto de las citas. También tienen una presencia destacada textos procedentes de una obra encargada por Carlos V Recopilación de Leyes de estos Reynos, publicada en 1567 en dos tomos de nueve libros. Así 
pues, cerca del 5\% de las citas de las Empresas políticas provienen de obras de carácter jurídico.

Las citas de la Política de Aristóteles ocupan otra importante parcela en las muestras de erudición de Saavedra. Es una obra que parece conocer muy bien. Da la impresión de que dedidó una parte de su «codex excerptorius» a recopilar sentencias de Aristóteles a lo largo de bastantes años; ello justificaría que las citas, que siempre da en latín, aunque a menudo proceden de la traducción realizada por Juan Ginés de Sepúlveda (1548), no siempre provienen de esa fuente. Es probable que en sus años de estudios en la Universidad de Salamanca realizara ejercicios de comentarios sobre esta obra de Aristóteles, que siguió interesándole largo tiempo. De hecho, dejando aparte la República Literaria, la primera obra con que se estrena Saavedra y que envía al conde-duque de Olivares en 1631, junto con la Razón de Estado del rey Católico don Fernando, es el opúsculo Introducciones a la política, que no es más que un condensado comentario de la Política de Aristóteles siguiendo todos sus pasos: que la compañía civil o política es natural al hombre, de la ciudad, de aspectos de la sociedad, de las formas de gobierno ${ }^{18}$... Aristóteles suponía una cómoda vía intermedia para no manifestarse abiertamente en torno a las polémicas y enfrentamientos ideológicos y políticos del momento; evitaba optar por los extremos: la obra de Maquiavelo y la lectura política de la Biblia.

Séneca es la otra influencia que destaca, y no es de extrañar. Si Tácito era una fuente de "prudentia» política, Séneca suponía una guía práctica para vivir conforme a la virtud que corresponde a un dirigente político; era fuente de «sapientia», la virtud del sabio estoico (el «sapiens») que afronta la adversidad con constancia y está dispuesto a asumir responsabilidades públicas, porque le preocupan los seres humanos cuyos sufrimientos le provocan misericordia. El «sapiens» vive de acuerdo con la virtud y la razón, acorde con la naturaleza, libre de emociones como ira, temor o esperanza. Distingue correctamente entre las cosas que son indiferentes (riqueza, salud, éxito, etc.) y sabe distinguir entre cosas que deben preferirse («proegmena») y las que deben rechazarse. Y por último, el «sapiens» ha de usar bien su «otium» para alcanzar el «negotium animi» y progresar en filosofia ${ }^{19}$. Cualquier hombre con responsabilidades públicas convenía que se educase en estos criterios. De las obras de Séneca, las más admiradas por autores que habían renovado un interés por este autor en el Renacimiento eran las de carácter ético, cuya excelencia radicaba tanto en el estilo como en la materia y el tratamiento. Sus agudas sentencias, lúcidas y penetrantes, («acres», «argutae», «penetrantes» en palabras de Lipsio) y su estilo fueron muy admirados, por lo que se consideraban dos aciertos: brevedad con elocuencia y fuerza con fluidez. De las obras de Séneca, las citas empleadas por Saavedra proceden de las Epistolas morales, Dialogi, De beneficiis y De clementia.

18 Puede verse en la edición de la BAE, págs. 423-433.

19 El lugar clásico donde se precisa la definición de «sapiens» está en la Epilola 75 de Séneca. 
Del resto de los elementos considerados eruditos usa Saavedra con diferente profundidad. Es marcado el rechazo por el empleo de apólogos basados en la Mitología clásica. En la empresa 2, al recomendar que se cuide qué estatuas y pinturas se ponen en el palacio del joven príncipe, indica «porque si bien el buril y el pincel son lenguas mudas, persuaden tanto como las más facundas». Explica entonces que, mientras Alejandro Magno incita a buscar la gloria, las transformaciones de Júpiter incitan a la lascivia. E inserta un párrafo que faltaba en la primera edición, lo cual es muy significativo: ha de cargar las tintas contra la Mitología y el arte detrás del que se esconde. Nunca emplea como «exempla» motivos mitológicos, y si alude en la declaración a algún episodio de la Mitología lo hace casi siempre con sentido negativo, como en la empresa 69, en que identifica a los príncipes que gastan mucho con Briareos (gigantes mitológicos que tenían cincuenta cabezas y cien brazos ${ }^{20}$ ). Aún así, en algunas empresas (muy pocas) alude a temas mitológicos que vienen avalados por una larga tradición literaria clásica, como en la 69, en que cita a Eneas en su bajada a los infiernos con la rama dorada y la espada, luego a Ulises y Polifemo; en la 74, alude a Belona y Ceres; en la 68 habla de los Argonautas.

La acumulación de sentencias en torno a un mismo tema es en ocasiones tan desproporcionada que induce a pensar que acudió a una poliantea en busca de fuentes, pero no se ha podido probar, y puede deberse, sencillamente, a que había nutrido su «codex excerptorius» con abundantes citas o anécdotas en torno a un tema que le interesaba mucho, como por ejemplo en la empresa 9, sobre la envidia, que encadena muchas sentencias primero y luego se ve que emplea «exempla», que ha ido él probablemente acumulando en su cartapacio personal.

En conclusión, podemos decir que Saavedra ha seguido, como prosista asistido de las normas oratorias, las pautas que tratadistas como Caussin y otros recomendaban. Y podemos decir que las fuentes que emplea proceden en su inmensa mayoría de lecturas de primera mano y que da citas textuales. Ese mismo proceder se ve en la Corona gótica, en cuyo prólogo explica:

\begin{abstract}
Siendo pues confusa y escura la narración de aquellos siglos, ha sido conveniente abrille a esta historia ventanas a la margen, por donde le entre la luz, poniendo los fraginentos de los autores con que se ha compuesto, no de otra suerte que como se forma una imagen con piedras de varios colores o con plumas de diversas aves.
\end{abstract}

Saavedra, pues, se nos muestra un intelectual con una excelente formación oratoria y dispuesto a alardear de ella ante personas de influencia en la corte, ya fueran civiles o eclesiásticas. Esta formación libresca y esta estimación exagerada de una cultura

20 Justo Lipsio identificaba al comienzo del libro III de sus Politicas al rey imprudente con Polifemo ciego (pág. 71 ed. cit.), porque antes había dicho, siguiendo a Cicerón, que la prudencia es el ojo del alma (pág. 26). 
programada limita con frecuencia la espontaneidad, y ese cúmulo de erudición, a nuestros ojos de hoy, lejos de servirle de ayuda, nos parece que supone una rémora. Sin embargo, no podemos olvidar el contexto en que se produjeron las Empresas y la valoración que entonces hubo de darse a estas muestras de dominio de una técnica y unas lecturas destinadas a un fin práctico y volcado en el servicio público: enseñar habilidad política, prudencia y sagacidad extraída de sus conocimientos de la Historia pasada y de la contemporánea, de la que él estaba excepcionalmente informado gracias a su profesión. 